\title{
Impaired polymorphonuclear leucocyte chemotaxis in rheumatoid arthritis
}

\author{
D. H. GODDARD, A. P. KIRK, J.R. KIRWAN, G. D. JOHNSON, AND \\ E. J. HOLBOROW
}

From the M.R.C. Immunology Section, Bone and Joint Research Unit, The London Hospital Medical College, Turner Street, London E1

SUMMARY This study has investigated the chemotactic activity of polymorphonuclear cells (PMNs) isolated from the blood of patients with either articular rheumatoid arthritis (RA) or RA with extra-articular manifestations. A double fluorochrome immunofluorescent staining test has been employed to identify cell-associated immunoglobulins, probably immune complexes. The results suggest an inverse relationship between PMN chemotaxis and staining for cell-associated immunoglobulins, either surface bound or internalised. PMNs from RA patients showed reduced chemotaxis, and this was further reduced when RA PMNs were incubated for 30 minutes in autologous serum. A similar reduction in chemotaxis of normal PMNs occurred after incubation in RA sera. Preincubation of both RA and normal PMNs in RA serum (but not normal serum) resulted in an increase in the number of cells in which cell-associated immunoglobulins were demonstrable. This further reduction in RA PMN chemotaxis after exposure to autologous serum, together with an increase in immunoglobulin staining, may indicate selection of certain PMNs at the time of venepuncture due to cell margination. Such a selection process would call for a re-evaluation of previous studies of RA PMN function in relation to the disease process.

In a study of polymorphonuclear (PMN) chemotaxis Mowat and Baum ${ }^{1}$ found impaired chemotax is in RA blood PMNs and suggested that this might account for the increased morbidity and mortality from serious infections claimed to occur in these patients. Subsequent studies ${ }^{2-4}$ have failed to confirm these findings. It was shown, however, that normal PMN chemotaxis is impaired after exposure to RA serum and serum from patients with other diseases. ${ }^{135-11}$ Mowat and Baum ${ }^{1}$ suggested that impaired PMN chemotaxis might result from the phagocytosis of soluble immune complexes by polymorphonuclear cells. Other serum factors have been identified which have been shown to inhibit chemotaxis, and a specific chemotaxis inhibitory factor recently reported by Hanlon $e t$ al. ${ }^{3}$ may play a part in regulation of the acute inflammatory response.

Goddard et al., ${ }^{12}$ using direct immunofluorescence tests, have demonstrated immunoglobulin inclusions in PMNs isolated from the blood of patients with RA. These were thought to represent phagocytosed

Accepted for publication 8 June 1983 .

Correspondence to Dr D. H. Goddard, Department of Rheumatology, Westminster Hospital, Horseferry Road, London SW1P 2AP. immune complexes, as similar inclusions developed in normal cells after exposure to RA sera known to contain raised levels of immune complexes but not after exposure to normal serum.

In this study we have investigated PMN chemotaxis in patients with rheumatoid arthritis and related these findings to the uptake of soluble immune complexes. We have also looked for any differences in function of cells isolated from the blood of patients with either articular RA or RA with extra-articular manifestations.

\section{Materials and methods}

Subjects studied. Twenty-two patients with definite or classical $\mathrm{RA}^{13}$ were studied and 17 sex-matched, healthy laboratory staff served as controls. All patients were assessed by an independent clinician and assigned to one of 2 groups: articular RA or RA with systemic features.

Isolation of PMNs from peripheral blood. A modification of the method described by Dioguardiet al. ${ }^{14}$ was used: $10 \mathrm{ml}$ of heparinised venous blood $(100$ units preservative-free heparin, Evans Laboratories 
Ltd., Liverpool, England) was mixed with $70 \mathrm{ml}$ of $0.83 \%$ ammonium chloride solution. Samples were gently mixed and allowed to stand until a colour change (red to brown) denoted erythrocyte lysis had occurred. Samples were then centrifuged at $120 \mathrm{~g}$ for 10 minutes at $4^{\circ} \mathrm{C}$, after which the supernatants were discarded and the process repeated. This eliminated erythrocytes from the preparation. The pellet was then suspended in medium $199+10 \%$ fetal calf serum (FCS) (Gibco Ltd, Irvine, Scotland), $\mathrm{pH} 7 \cdot 4$, at $4^{\circ} \mathrm{C}$, and the cells were centrifuged at $55 \mathrm{~g}$ for 10 minutes. The supernatants containing lymphocytes were discarded and the washing process repeated twice more. The final PMN preparation contained approximately $6 \%$ lymphocytes and $1 \%$ monocytes and approximately $70 \%$ of the original cell numbers. PMN viability was assessed by trypan blue exclusion and was $>98 \%$. PMNs were adjusted to a final concentration of $1 \times 10^{10} / \mathrm{ml}$ for direct immunofluorescence (IF) and $2 \times 10^{6} / \mathrm{ml}$ for incubation experiments.

Cell migration studies. A modification of the Boyden technique described by Howe et al. ${ }^{4}$ was used. $200 \mu \mathrm{l}$ of PMN suspension $\left(12 \times 10^{6} / \mathrm{ml}\right)$ were centrifuged on to cellulose ester filters $(3 \mu \mathrm{m}$ pore size: Schlier and Schull Ltd), at $450 \mathrm{rpm}$, using a Shandon Cytocentrifuge (Shandon Southern Ltd). The filters were then mounted in Sykes Moore chambers. The upper compartment was filled with Hanks's balanced salt solution (HBSS) (Wellcome Reagents Ltd), $\mathrm{pH} 7 \cdot 3$. The lower compartment was filled with either HBSS to measure random migration or $10 \%$ casein-activated pooled $A B$ serum in HBSS to measure chemotaxis. Preliminary experiments (results not shown) constructing checker-board analysis confirmed that this was chemotactic for PMNs.

The chambers were incubated at $37^{\circ} \mathrm{C}$ for 20 minutes. The filters were then fixed overnight in SUSA solution, rinsed in acid alcohol for 2 minutes, then in distilled water for 15 minutes. Next the filters were rendered basic by rinsing in 'blueing agent' $(2 \mathrm{~g}$ $\left.\mathrm{NaHCO}_{3}, 20 \mathrm{~g} \mathrm{MgSO}_{4} / \mathrm{l}\right)$ for 2 minutes, dehydrated in absolute alcohol for 3 minutes, cleared in xylene and mounted in immersion oil (Fractoil, Raymond and Lambe, London).

The 2-cell leading front measurement was determined for all subjects by the method of Zigmond and Hirsch. ${ }^{15}$ With a $\times 100$ oil immersion objective 5 random readings were taken from each of the duplicate filters. The chemotactic indices were calculated by subtracting the mean value for random migration from the mean value for direct migration and the result expressed as a percentage of the control value.

Incubation experiments. PMN suspensions $\left(2 \times 10^{6} / \mathrm{ml}\right)$ in medium $199+10 \%$ FCS were incubated with $100 \mu \mathrm{l}$ of rheumatoid serum at $37^{\circ} \mathrm{C}$ for 30 minutes in a water-bath. After 30 minutes further phagocytosis was stopped by rapidly cooling cells to $4^{\circ} \mathrm{C}$ in an ice-bath. Cells for IF staining were washed twice in ice-cold M119+10\% FCS. Cells for migration experiments were washed twice in ice-cold HBSS, and these samples were adjusted to a final concentration of $12 \times 10^{6} / \mathrm{ml}$.

Double fluorochrome staining of PMNs. This method has recently been described by Johnson et $a l .{ }^{16}$ and is based on the use of paired fluorescent conjugates of identical specificity, labelled with either fluoresce in or rhodamine. PMNs in suspension are incubated with one conjugate, washed and transferred to glass slides by cytocentrifugation, fixed, and restrained with the alternative conjugate.

After washing, PMNs were resuspended in $50 \mu \mathrm{l}$ of class-specific fluorescein-conjugated antiglobulin (Wellcome Reagents Ltd.) diluted 1:10 in phosphate-buffered saline (PBS), $\mathrm{pH} 7 \cdot 4$, containing $2 \%$ bovine serum albumin (BSA). Cells were incubated at $4^{\circ} \mathrm{C}$ for 60 minutes. Cells were then washed once in PBS containing 2\% BSA, twice in M199+10\% FCS, and resuspended in the latter at a final concentration of $1 \times 10^{6} / \mathrm{ml}$, before centrifuging on to cleaned glass slides using a Shandon Cytocentrifuge. After being dried at room temperature the slides were fixed in acetone at room temperature for 30 minutes. At this stage the slides were stored in plastic bags at $-20^{\circ} \mathrm{C}$ prior to counterstaining with rhodamine-conjugated antiglobulins of identical specificity.

Corresponding rhodamine-labelled anti- $\gamma$ and anti- $\mu$ conjugates were kindly supplied by $\operatorname{Dr} S$. Chantler (Wellcome Research Laboratories, Beckenham, England) who also supplied sheep anti-C3 antiserum which was labelled with TRITC by the method of Amante et al. ${ }^{17}$

The specificity of these antiglobulin reagents was confirmed by direct staining of monoclonal bone marrow preparations ${ }^{18}$ and of anticomplement activity by indirect immunofluorescence of cryostat sections of stomach treated with serum containing parietal cell antibody with and without fresh human serum. ${ }^{19}$

Slides were counterstained with rhodamine conjugates of identical specificity (diluted 1:15 in PBS $+2 \%$ BSA) for 60 minutes at room temperature. After being washed in several changes of PBS the slides were mounted in $\mathbf{9 0 \%}$ glycerol in PBS; bleaching of immunofluorescence was minimised by the addition of $0.01 \mathrm{M}$ paraphenylenediamine to the mountant. $^{20}$ The fluorescence microscope was equipped with narrow-band filters for incident illumination with an HB 050 mercury lamp.

PMNs were scored for the presence of cellassociated immunoglobulins. The differential staining 
test allowed a clear discrimination to be made between surface immunoglobulins stained by both fluorochromes, which appeared golden yellow, and internalised immunoglobulins staining with rhodamine alone, which appeared as red granules.

One hundred PMNs were scored in each of 3 areas of the slide for inclusions, and the mean of these results was taken.

\section{Results}

PMN migration. The chemotactic index of RA PMNs was reduced to $70 \%$ of the normal control value ( $<<0.01$, paired $t$ test) (Fig. 1). This reduction in chemotaxis was equal in the 2 patient groups (articular and systemic). The random motility of RA PMNs (mean $63 \mu \mathrm{m}$ ) was the same as that of controls (mean $60 \mu \mathrm{m})$. Directed motility was reduced to $102 \mu \mathrm{m}$ compared with the controls of $114 \mu \mathrm{m}(\mathrm{p}<0.05$, paired $t$ test).

Immunoglobulins inclusions. Immunoglobulin inclusions were detected in some PMNs from 17 of the 22 patients with RA (77\%) but in none of the control PMNs. IgG inclusions were found in PMNs from 13 patients $(63 \%), \operatorname{IgM}$ in 15 patients $(68 \%)$, and C3 in 14 patients (65\%). IgM inclusions were found more frequently in cells from patients with systemic disease ( $90 \%$ of patients) than in articular disease $(50 \%)$. The overall proportion of PMNs from systemic RA patients containing inclusions of IgM was greater than in patients with articular disease $(4.2 \%, p<0.05$, paired $t$ test $)$. The proportion of PMNs containing IgG inclusions (16\%) and C3 inclusions $(5 \%)$ was the same in both groups of patients (Fig. 2). Almost all the cells containing inclusions were also shown to have surface-bound immunoglobulins (Fig. 3).

Effects of RA serum on normal PMN migration. Incubation of normal PMNs in normal (pooled AB) control serum had no effect on either random or directed migration. Immunoglobulin inclusions did not develop in these cells after incubation in this serum.

When normal PMNs were preincubated in RA serum (from patients with either articular or systemic disease) their chemotactic index was reduced to $31 \%$ of their initial value $(76 \mu \mathrm{m})$ (Fig. 1). The random motility of these cells was not affected by these sera. Some PMNs developed immunoglobulin inclusions after incubation in all but one of the RA sera (from a patient with articular disease). Immunoglobulin inclusions developed in a similar proportion of cells exposed to these sera (Fig. 2). Almost all the cells containing inclusions were also found to have surface-bound immunoglobulins (Fig. 3).

Effects of autologous serum on RA PMN migration. The chemotactic index of RA PMNs was reduced to $30 \%$ of the normal control value (i.e. $43 \%$ of the preincubation value) after incubation in autologous serum (Fig. 1). Immunoglobulin inclusions
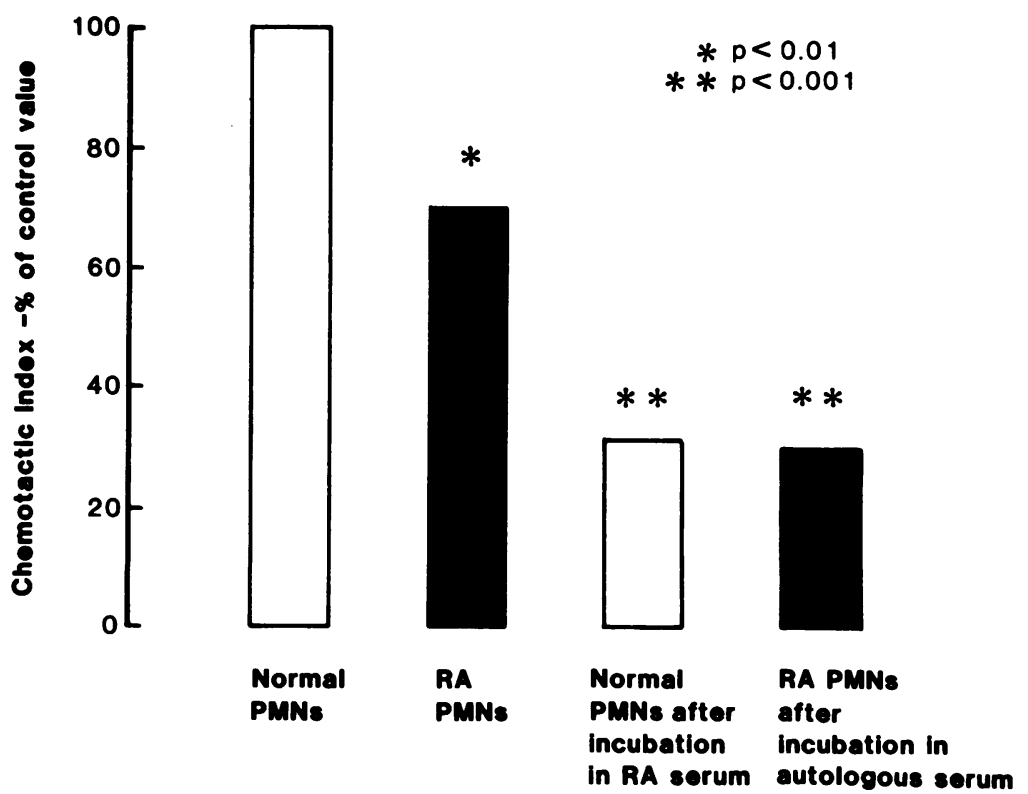

Fig. 1 Chemotactic index of RA and normal blood PMNs. 


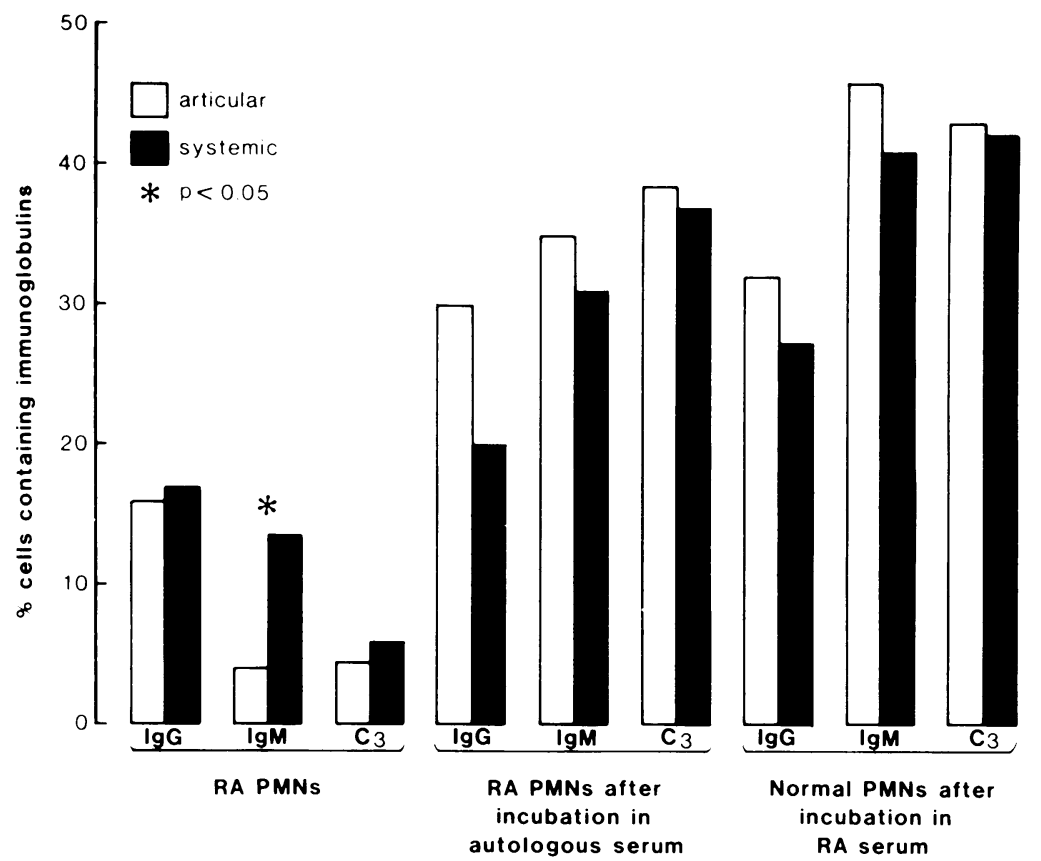

Fig. 2 Immunoglobulin inclusions in RA and normal blood PMNs.
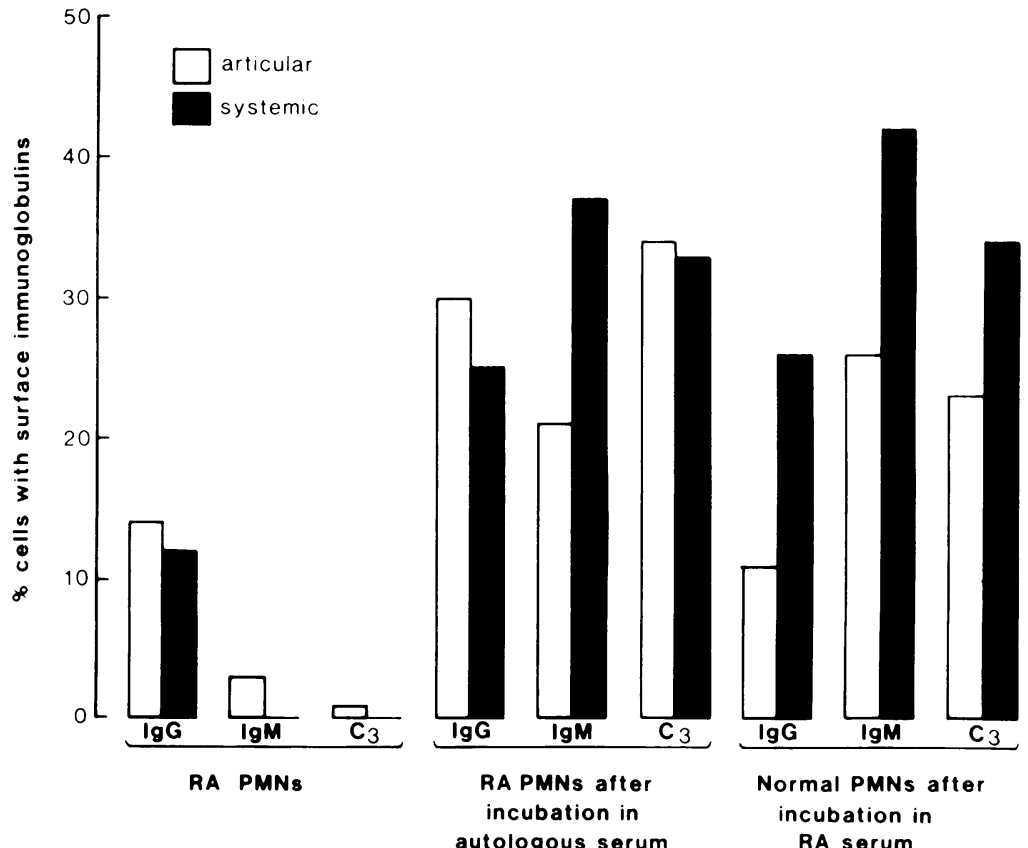

Fig. 3 Surface bound immunoglobulins in RA and normal blood PMNs.

developed in a similar proportion of cells exposed to these sera (Fig. 2), and almost all the cells containing inclusions were also found to have surface-bound immunoglobulins (Fig. 3).

\section{Discussion}

In this study we have used the micropore filter assay to measure PMN migration, and have demonstrated 
a significant reduction in directed but not random motility of PMNs isolated from the blood of patients with systemic and articular rheumatoid arthritis. This result is in agreement with the findings of Mowat and Baum. ${ }^{1}$

Using the technique of double fluorochrome immunofluorescence we have been able to discriminate between surface-bound and internalised immunoglobulins associated with these cells, and have shown that IgM inclusions occur more frequently in PMNs from patients with systemic RA than in those from patients with articular disease. The overall proportion of cells containing IgM inclusions was, however, small. IgG and C3 inclusions occurred in a similar proportion of PMNs $(15 \%$ and $5 \%$ respectively) in articular and systemic disease.

Following incubation for 30 minutes in RA serum normal PMNs showed a large reduction in chemotaxis, and $40 \%$ of cells were found to have developed immunoglobulin inclusions. The moderate reduction in RA PMN chemotaxis was further reduced after 30 minutes' incubation in autologous serum, and the proportion of immunoglobulincontaining cells had increased to $35 \%$. These changes were similar to those observed after normal PMNs were incubated in RA serum.

These results suggest an inverse relationship between immunoglobulin staining, which we believe represents staining of immune complexes, and chemotaxis. Most of the PMNs staining for immunoglobulins showed surface-bound immunoglobulins as well as internalised immunoglobulins, and it is therefore impossible to separate their effects in this study. It is probable, however, that surface binding and internalisation of immune complexes affect chemotaxis in different ways. Wilkinson ${ }^{21}$ has recently reported that IgG aggregates can both stimulate and inhibit PMN chemotaxis. One possibility is that immunoglobulins bound to the surface of cells may impede locomotion $^{22}$ and thus reduce chemotaxis, while internalised immunoglobulin may actually stimulate chemotaxis. In the succeeding paper $^{23}$ we have investigated the effects of $\operatorname{IgG}$ aggregate uptake on normal PMN motility.

We were surprised to find that RA PMNs showed a further reduction in chemotaxis after exposure to autologous serum. This finding suggests that RA PMNs are capable of undertaking further phagocytosis in vitro but not apparently in vivo in spite of raised levels of immune complexes in these patients, when only some RA PMNs had detectable cell-associated immunoglobulins. Since uptake of immune complexes may alter other cell properties, such as cellular adherance to the vascular endothelium (i.e. the first stage of margination), these cells would not be sampled at the time of vene- puncture, while the sample would contain PMNs which had yet to undertake the task of phagocytosis of immune complexes. The operation of such a selection process would call for a re-evaluation of the previous studies of RA PMN function in relation to the disease process.

\section{References}

1 Mowat A G, Baum J. Chemotaxis of polymorphonuclear leucocytes from patients with rheumatoid arthritis.J Clin Invest 1971; 50: $2541-4$.

2 Goetzl E J. Defective responsiveness of ascorbic acid of neutrophil random and chemotactic migration in Felty's syndrome and systemic lupus erythematosus. Ann Rheum Dis 1976; 35: $510-5$.

3 Hanlon S M, Panayai G S, Laurent R. Defective polymorphonuclear leucocyte chemotaxis in rheumatoid arthritis associated with a serum inhibitor. Ann Rheum Dis 1980; 39: 68-74.

4 Howe G B, Fordham J N, Brown K A, Currey H L F. Polymorphonuclear cell function in rheumatoid arthritis and Felty's syndrome. Ann Rheum Dis 1981; 40: 370-5.

5 DeMeo A N, Anderson B R. Defective chemotaxis associated with a serum inhibitor in cirrhotic patients. N Engl J Med 1972; 286: $735-40$.

6 Smith C W, Hollers J C, Dupree E, et al. A serum inhibitor of leucotaxis in a child with recurrent infections. J Lab Clin Med 1972; 79: 878-85.

7 Ward P A, Berenberg J L. Defective regulators of inflammatory mediators in Hodgkin's disease. Supernormal levels of chemotactic factor inactivator. N Engl J Med 1974; 290: 76-80.

8 Van Epps D E, Palmer D L, Williams R C Jnr. Characterisation of serum inhibitors of neutrophil chemotaxis associated with anergy. J Immunol 1974; 113: 189-200.

9 Van Epps D E, Strickland R G, Williams R C Jnr. Inhibitors of leucocyte chemotaxis in alcoholic liver disease. Am J Med 1975; 59: 200-7.

10 Maderazo E G, Ward P A, Woronick C L, et al. Leucocyte dysfunction in sarcoidosis. Ann Intern Med 1976; 84: 414-9.

11 Ward P A, Goralnick S, Bullock W E. Defective leucotaxis in patients with lepromatous leprosy. J Lab Clin Med 1976; 87: 1025-32.

12 Goddard D H, Brown K A, Kirk A P, McCarthy D, Johnson G D, Holborow E J. Immunoglobulin inclusions in rheumatoid arthritis polymorphonuclear cells: lack of correlation with circulating immune complexes. Rheumatol Int 1982; 2: 27-30.

13 Ropes M W, Bennett G A, Cobb S, et al. Revision of diagnostic criteria for rheumatoid arthritis. Bull Rheum Dis 1958; 9: 175-6.

14 Dioguardi N, Agostini A, Fiorelli G, Lomanto B. Characterisation of lactic dehydrogenase of normal human granulocytes. $J$ Lab Clin med 1963; 61: 713-25.

15 Zigmond S H, Hirsch J G. Leucocyte locomotion and chemotaxis. New methods for evaluation and demonstration of cell-derived chemotactic factors. J Exp Med 1973; 137: $387-410$.

16 Johnson G D, Goddard D H, Holborow E J. Differential immunofluorescence staining of polymorphonuclear leucocytes for discrimination between surface bound and internalised immunoglobulin. J Immunol Methods 1982; 50: 280.

17 Amante L, Ancona A, Forni L. The conjugation of immunoglobulins with tetramethylrhodamine isthiocynate: a comparison between amorphous and crystalline fluorochrome. $J$ Immunol Methods 1972; 1: 289-301.

18 Van Furth R, Schmit H R E, Hijmans $H$. The formation of immunoglobulins by human tissues in vitro-the methods and their specificity. Immunology 1966; 11: 1-15. 
19 Johnson G D, Holborow E J, Dorling J. In: Weir D M, ed. Handbook of experimental immunology. Oxford: Blackwell, 1978: 15-7.

20 Johnson G D, Araujo G M. A simple method of reducing the fading of immunofluorescence during microscopy. $J$ Immunol Methods 1981; 43: 349-50.

21 Wilkinson P C. Effects of human IgG on locomotion of human neutrophils related to IgG binding of a hydrophobic probe Immunology 1980; 4: 457.

22 Keller H U, Sorkin E. Chemotaxis in leucocytes. Experientia 1968; 35: 641-52.

23 Goddard D H, Kirk A P, Brown K A, McCarthy D, Johnson G D, Holborow E J. Changes in normal polymorphonuclear leucocyte motility after ingestion of IgG aggregates. Ann Rheum Dis 1984; 43: 146-150.

\section{Book review}

Recent Advances in Rheumatology. No. 3. Eds. W. Carson Dick and J. M. H. Moll. Pp. 239. £24.00. Churchill Livingstone: Edinburgh. 1983.

Dr W. Carson Dick and Dr J. M. H. Moll are to be congratulated on their editing of this volume. The contents reflect the broad interdisciplinary approach on which understanding of the rheumatic diseases has progressed through the last decade.

Although the speculative gap between animal diseases associated with arthritis and various rheumatic diseases seems not to have narrowed, a reading of the first chapter (D. Bennett and F. Goodacre) will rekindle interest in tantalising analogies. Similarly, the account of the pattern of parasitic and infectious disease associated with arthritis in the African continent (S. Brighton) and the relatively low prevalence of rheumatoid arthritis provides perspective in any consideration of temperate zone problems. The account of studies exploiting monoclonal antibodies (A. R. MacKenzie and A. R. Williamson) and an updated summary of the relevance the major histocompatibility system has to rheumatic disorders (K. Welsh and C. M. Black) are valuable. Further advances in the understanding of rheumatoid arthritis in particular are likely to result from a synthesis of these approaches. Chapters describing the molecular structure of the connective tissues (J. P. Pearson) and rheumatoid pathology (B. Vernon-Roberts) are both well written and useful summaries.

Finally there are four chapters of direct clinical interest. A refreshing account of the myopathies (P. Hudgson), orthopaedic management (G. Bentley and G. S. E. Dowd), and the uncertainties of 'immune manipulation' (R. S. Amos and D. J. Walker) are summaries of current practices. The final chapter (V. Wright) will be a useful reference to the available methods of assessment in rheumatology, but the problem of devising an accurate, reproducible and time efficient means of assessing the arthritic patient under clinic conditions is obviously no closer to solution.

This book, although selective in scope, will be particularly helpful to those training in the specialty. Despite the editors' preface relating to the arbitrary choice of what is to be regarded as either recent or an advance, the potential reader would be better guided to the scope of this text had the review format of the contributions been reflected in the title.

D. G. PALMER 